\title{
Effect of Steroid Hormone (Ecdysone) on the Pupal and Larval Developments of Tribolium castaneum (Herbst)
}

\author{
Dipali Rani Das, S. I. Faruki, A.M. Saleh Reza and Selina Parween* \\ Department of Zoology, Rajshahi University, Rajshahi 6205, Bangladesh
}

\begin{abstract}
Ecdysone is a steroid hormone especially found in insects and mammals. One day old pupae of Tribolium castaneum were exposed to crude ecdysone at different concentrations of 10, 20, 40, 80, 160, and $320 \mu \mathrm{l} / \mathrm{kg}$ of whole wheat flour each for 1 , 3 and 5 days. Adult recovery was significantly reduced in the treated pupae $(\mathrm{F}=3.47, \mathrm{P}<0.01, \mathrm{df}=7)$, and produced deformed individuals $(\mathrm{F}=39.29, \mathrm{P}<0.001, \mathrm{df}=7)$ at all exposure periods. The developmental time was similar in both the treated and untreated ones. The latent effect of the ecdysone treatment increased both the larval $(\mathrm{F}=4.26, \mathrm{P}<0.001, \mathrm{df}=7)$ and pupal $(\mathrm{F}=8.56, \mathrm{P}<0.001, \mathrm{df}=7)$ periods of the progeny reared on untreated foods. Similarly, the latent effect hampered recovery of the adult progeny $(\mathrm{F}=7.79, \mathrm{P}<0.001, \mathrm{df}=7)$ producing deformed individuals $(\mathrm{F}=2.65$, $\mathrm{P}<0.05, \mathrm{df}=7$ ).
\end{abstract}

Key words: Ecdysone, T. castaneum, Developmental period, Adult recovery.

\section{Introduction}

Stored grains, processed grain products, and other commodities are susceptible to insect pest infestation under the tropical climatic factors. In Bangladesh, both storage conditions and the environmental factors enhance losses of stored products by insect infestation and fungal contamination. Though the chemical insecticides produced some hazards and disadvantages for the environment and human health, still these have prime importance in insect management programmes in both agriculture and post-harvest storage systems. In search of alternatives to chemical insecticides and eco-friendly compounds, the Insect Growth Regulators (IGRs) showed good results against the insect pests of stored products (Strong and Diekman, 1973). As IGRs mimic the natural hormones present in the insects (Williams, 1956), hence they are safe for the non-target organisms (Fox, 1990). IGRs are consisted of three groups of hormones, which are juvenile hormones, ecdysones and moult inhibitors. The natural ecdysone is a steroid hormone present in insects, triggers moulting in immature stages and follow up their metamorphoses (Reza et. al., 2004) in presence of the juvenile hormone (Riddiford, 1985). Free ecdysone has been reported to be involved in the control of meiotic reinitiation in the oocytes of insects (Lanot et. al., 1989).

Synthetic edysones/ecdysteroids have been reported to produce effective control in the population of lepidopteran pests of different crops (Wing and Aller, 1990). Hami et. al. (2006) reported that ecdysteroid exhibited excellent potentiality in controlling moths of stored products. Ecdysone treatment to larval stage leads to primitive cuticle synthesis, especially around the head region resulting in feeding inhibition due to abnormalities of functional mouth parts (Wing and Aller, 1990). Ecdysone titre in pupa results in normal adult eclosion. Synthetic ecdysteroids have both stomach and contact actions against lepidopterous, coleopterous and dipterous insects (Fox, 1990), affecting their normal developments. Published reports on insecticidal effects of crude ecdysone or synthetic ecdysteroids against the stored product beetles are very scanty.

The present research was aimed at to assess the direct and latent effects of crude ecdysone on their developments and metamorphoses in the next $\left(\mathrm{F}_{1}\right)$ generations when the pupae of red flour beetle, Tribolium castaneum (Herbst) were exposed to treated foods.

\section{Materials and Methods}

\section{Insect used}

The laboratory strain of Tribolium castaneum was used for this experiment as a model insect which is also a major pest of a variety of stored products throughout the world.

\section{Ecdysone}

Crude ecdysone was used at concentrations of 10, 20, 40, 80, 160, 320 and $640 \mu l$. Each of these quantities of ecdysone was taken by a micro pipette, mixed with $10 \mathrm{ml}$ of acetone.

\footnotetext{
* Corresponding author: E-mail: parween_s@yahoo.com
} 
This mixture was then mixed thoroughly with 1 kilogram of flour by using an electric blender. The treated flour kept uncovered at room temperature for evaporation of the acetone.

\section{Experimentation}

Adults of T. castaneum from the stock culture were collected and subcultures were established on sterilized whole wheat flour at $30+1{ }^{\circ} \mathrm{C}$ in an incubator without controlling light and humidity. From these subcultures, 1-day old pupae were collected for the experiment. The collected pupae were sexed according to Halstead (1963). Male and female pupae were exposed to the ecdysone-treated flour separately until adult emergence.

\section{Experiment I}

Twenty 1-day old pupae of both the sexes were used separately for each concentration of ecdysone. The pupae were exposed to treated flour for 1,3 and 5 consecutive days. After exposure, the treated pupae were kept separately according to ecdysone concentration, sex and exposure period in glass Petri dishes (6 cm diameter) at room temperature (15-17 OC) up to adult emergence. For Control batch, 20 male and 20 female pupae were kept in untreated flour up to five days. After five days all the pupae of treated and untreated batches were replaced in other set of Petri dishes without food at the same temperature. The experiment was replicat ed three times. The pupal period, percentage of adult recovery and number of deformed individuals were recorded for the treated (each concentration and exposure levels) and the untreated ones.

\section{Experiment II}

From the experiment I, 10-day old male and female adults were collected from each concentration of hormone treatment and for each exposure period. Five pairs of adults were allowed to mate for four days on untreated flour in Petri dish. The adults were then removed. The eggs in the flour were kept for 10 days and the live larvae thus obtained were replaced in a new Petri dish with fresh untreated flour. After each five day, the flour medium was changed by fresh one to avoid conditioning. Larvae were carefully checked until they pupated. The larval period was noted and the pupal recovery (\%) was determined. The pupae were removed from flour and kept for adult eclosion. The pupal period was recorded along with adult recovery (\%). Number of deformed individuals was also recorded.

Five pairs of adult were introduced into the untreated control batch under the same condition and termed as Control. All the experiments using treated and untreated T. castaneum, were replicated three times and conducted at room temperature (15-17 OC) and relative humidity (average 70\%).

Table I. Effect of exposure to different periods of 1-day old pupae of $T$. castaneum $(\mathrm{N}=30)$

\begin{tabular}{|c|c|c|c|c|}
\hline \multirow[t]{3}{*}{ Parameter } & \multirow[t]{3}{*}{ Concentrations $(\mu \mathrm{l} / \mathrm{kg})$} & \multicolumn{3}{|c|}{ Exposure periods } \\
\hline & & 1-day & 2-day & 3-day \\
\hline & & Mean \pm SE & Mean \pm SE & Mean \pm SE \\
\hline \multirow{8}{*}{ Pupal period (day) } & 0 (Control) & $6.00 \pm 0.29$ & $6.00 \pm 0.29$ & $6.00 \pm 0.29$ \\
\hline & 10 & $6.50 \pm 0.50$ & $6.50 \pm 0.50$ & $6.50 \pm 0.00$ \\
\hline & 20 & $6.50 \pm 0.29$ & $6.67 \pm 0.67$ & $6.50 \pm 0.50$ \\
\hline & 40 & $6.67 \pm 0.17$ & $6.83 \pm 0.60$ & $6.67 \pm 0.17$ \\
\hline & 80 & $6.83 \pm 0.60$ & $7.00 \pm 0.29$ & $6.83 \pm 0.60$ \\
\hline & 160 & $7.00 \pm 0.58$ & $7.00 \pm 0.29$ & $7.00 \pm 0.29$ \\
\hline & 320 & $7.00 \pm 0.00$ & $7.00 \pm 0.58$ & $7.00 \pm 0.50$ \\
\hline & 640 & $7.00 \pm 0.29$ & $7.50 \pm 0.29$ & $7.17 \pm 0.17$ \\
\hline \multirow{8}{*}{ Deformity (\%) } & 0 (Control) & $0.00^{\mathrm{a}}$ & $0.00^{\mathrm{a}}$ & $0.00^{\mathrm{a}}$ \\
\hline & 10 & $0.00^{\mathrm{a}}$ & $2.33 \pm 0.17^{\mathrm{ab}}$ & $0.00^{a}$ \\
\hline & 20 & $0.00^{\mathrm{a}}$ & $2.50 \pm 0.29^{a b}$ & $2.50 \pm 0.29^{a b}$ \\
\hline & 40 & $2.50 \pm 0.29^{a b}$ & $2.50 \pm 0.87^{a b}$ & $2.50 \pm 0.29^{\mathrm{ab}}$ \\
\hline & 80 & $2.50 \pm 0.87^{a b}$ & $2.50 \pm 0.87^{a b}$ & $5.00 \pm 1.73^{b}$ \\
\hline & 160 & $5.00 \pm 1.16$ abc & $5.00 \pm 1.73$ bc & $5.00 \pm 0.00^{b}$ \\
\hline & 320 & $7.50 \pm 1.45^{\text {bc }}$ & $5.00 \pm 1.00$ bc & $5.00 \pm 1.16^{b}$ \\
\hline & 640 & $10.00 \pm 1.73^{c}$ & $7.50 \pm 0.87^{c}$ & $5.00 \pm 0.58^{b}$ \\
\hline
\end{tabular}

N.B. Mean with the same letter are not significantly different relating to duration and metamorphosis. 
The direct and latent effects of ecdysone treatment at different levels of concentration and exposure periods were compared to the Control by Analysis of Variance (ANOVA). The effectiveness of each concentration of ecdysone was analysed by Tukey's Test of Multiple Comparisons (1953).

\section{Results and Discussion}

\section{Experiment I}

When 1-day old puape were exposed to ecdysone concentrations viz., 10, 20, 40, 80, 160, 320 and 640 l/kg of flour for 1, 3 and 5 days, no significant effect was observed on their pupal durations $(\mathrm{F}=1.79, \mathrm{df}=7$, concentration; $\mathrm{F}=0.19$, $\mathrm{df}=2$, exposure period) (Table I). The untreated pupae emerged as adults in 6.000 .29 days and the maximum time required was 7.500 .29 days at $640 \mu \mathrm{l} / \mathrm{kg}$ of ecdysone when exposed for 2 days (Table I). Ecdysone effect on the pupal period was found to be positively increased with the concentrations, and similar results were noticed at all exposure periods.

The average adult recovery was reduced to minimum 92.17\% which significantly differed from the recovery (100\%) from the untreated pupae $(\mathrm{F}=3.47, \mathrm{P}<0.01, \mathrm{df}=7)$ at 1-day exposure to $640 \mathrm{l} / \mathrm{kg}$ (Table II). However, the same concentration produced $95.00 \%$ adults in the batches exposed for 2 and 3 days, (Table II). Similar difference ofadult recovery was observed at all levels of concentration $(\mathrm{F}=1.87, \mathrm{P}<0.05, \mathrm{df}=14$, concentration exposure period). However, the percentage of adult recovery was determined form the total live adults emerged. The adult recovery was more affected at 1-day exposure to ecdysone level higher than $20 \mu \mathrm{l}$ whereas at longer exposures $100 \%$ eclosion was recorded at 20 and $40 \mu \mathrm{l}$ of ecdysone treatment (Table II).

Adult deformity (maximum $10 \%$ in average) was recorded among the adults emerged from the treated pupae at all con centration levels $(\mathrm{F}=39.29, \mathrm{P}<0.001, \mathrm{df}=7)$ and at each exposure period $(\mathrm{F}=0.60, \mathrm{P}>0.05, \mathrm{df}=2)$ (Table $\mathrm{I})$. The results revealed that ecdysone concentrations hampered the normal metamorphosis which was positively related with the concentrations used. The result reveals that exposure of the pupae to ecdysone for 1-day was more effective in disturbing the metamorphosis than the higher exposure times. The maximum abnormal individuals were found as $7.5 \pm 0.87(\%)$ and $5.00 \pm 0.58(\%)$ at 6401 when exposed for 2 and 3 days respectively (Table I).

\section{Experiment II}

This experiment was carried out to determine the latent effect of ecdysone due to contact action to the pupae of $T$. castaneum and also on their next progeny without any further treatment.

Development of the larval progeny was definitely retarded by ecdysone concentrations. The larvae elapsed for minimum 23.17 0.44 days to pupate in untreated control. Larval period in a single exposure period varied significantly with different concentrations ( $\mathrm{F}=4.26, \mathrm{P}<0.001$, $\mathrm{df}=7$ ). The maximum larval period (26.33 \pm 1.64 days) was observed at $160 \mathrm{l} / \mathrm{kg}$ at 1-day exposure, which were obtained as $27.33+$ 1.30 and $27.00 \pm 1.32$ days when the exposures were 3 and 5 days respectively at $640 \mathrm{l} / \mathrm{kg}$ (Table III).

In the progeny, the pupal period was more affected. The pupae obtained from untreated parent completed metamorphosis in $9.50 \quad 0.29$ days which was maximum $14.33 \quad 0.17$ days in those puape which were obtained form the parents exposed to 320 l/kg ecdysone for 5 days (Table III). The pupal period varied significantly at different concentration levels $(\mathrm{F}=8.56, \mathrm{p}<0.001$, $\mathrm{df}=7)$ at all exposure periods $(\mathrm{F}=$ $1.51, \mathrm{p}<0.05, \mathrm{df}=2)$. The pupal period was most affected in

Table II. Adult recovery percentage of $T$. castaneum when 1-day old pupae were exposed to ecdysone-treated food for different durations for adult emergence $(\mathbf{N}=30)$

\begin{tabular}{|c|c|c|c|c|c|c|}
\hline \multirow{3}{*}{$\begin{array}{l}\text { Concentrations } \\
(\mu \mathrm{l} / \mathrm{kg})\end{array}$} & \multicolumn{6}{|c|}{ Adult recovery (\%) at different exposure periods } \\
\hline & \multicolumn{2}{|c|}{ 1-day } & \multicolumn{2}{|c|}{ 2-day } & \multicolumn{2}{|c|}{ 3-day } \\
\hline & Mean \pm SE & PRC & Mean \pm SE & PRC & Mean \pm SE & PRC \\
\hline 0 (Control) & $100 \pm 0.00^{\mathrm{a}}$ & -- & $100 \pm 0.00^{\mathrm{a}}$ & -- & $100 \pm 0.00^{\mathrm{a}}$ & -- \\
\hline 10 & $100 \pm 0.00^{\mathrm{a}}$ & 0.00 & $100 \pm 0.00^{\mathrm{a}}$ & 0.00 & $100 \pm 0.00^{\mathrm{a}}$ & 0.00 \\
\hline 20 & $100 \pm 0.00^{\mathrm{a}}$ & 0.00 & $100 \pm 0.00^{\mathrm{a}}$ & 0.00 & $100 \pm 0.00^{\mathrm{a}}$ & 0.00 \\
\hline 40 & $97.5 \pm 1.32^{\mathrm{a}}$ & 2.50 & $100 \pm 0.00^{\mathrm{a}}$ & 0.00 & $100 \pm 0.00^{\mathrm{a}}$ & 0.00 \\
\hline 80 & $97.5 \pm 1.32^{\mathrm{a}}$ & 2.50 & $100 \pm 0.00^{a}$ & 2.50 & $97.5 \pm 1.16^{\mathrm{ab}}$ & 2.50 \\
\hline 160 & $97.5 \pm 1.16^{\mathrm{a}}$ & 2.50 & $97.5 \pm 1.00^{\mathrm{ab}}$ & 2.50 & $97.5 \pm 1.04^{\mathrm{ab}}$ & 2.50 \\
\hline 320 & $97.5 \pm 1.76^{\mathrm{a}}$ & 2.50 & $97.5 \pm 1.53^{a b}$ & 2.50 & $97.5 \pm 1.16^{\mathrm{ab}}$ & 0.00 \\
\hline 640 & $92.17 \pm 1.17^{b}$ & 7.83 & $95.00 \pm 2.08^{b}$ & 5.00 & $95.00 \pm 2.00^{b}$ & 5.00 \\
\hline
\end{tabular}

N.B. Means with the same letter are not significantly different. 
the progeny which evolved from $80 \mathrm{l} / \mathrm{kg}$ ecdysone at all exposure levels (Table III).

Pupal recovery (\%) of the progeny was insignificantly differed among the ecdysone treated and untreated populations $(\mathrm{F}=0.94, \mathrm{df}=7)$, but showed a significant $(\mathrm{p}<0.05)$ difference among the batches with different exposure periods $(\mathrm{F}=4.18$, $\mathrm{df}=2$ ), (Table IV).

In control batch the adult recovery was $99.49 \%$ (Table IV). Significant reduction of adult recovery was found among the progeny of ecdysone treated beetles at all concentrations $(F=7.79, p<0.001, d f=7)$ irrespective of the exposure periods $(\mathrm{F}=0.66, \mathrm{p}>0.005, \mathrm{df}=2)$. The percentage of reduction in adult numbers was not related to the ecdysone concentration at any exposure regime (Table IV). The maximum reduction of emergence was $11.83 \%$ when the parental generation exposed to $320 \mu \mathrm{l} / \mathrm{kg}$ ecdysone for 1 day (Table IV).

Among the treated progeny a small percentage of deformed individuals were observed (Table III) at all concentration levels and exposure periods. Significant differences were observed in the experiments conducted on concentrations $(\mathrm{F}=2.65, \mathrm{p}<0.05, \mathrm{df}=7)$.

The central role of ecdysone is to initiate and coordinate moults and metamophoses in insects (Riddiford, 1985). At each moult, the level of ecdysone within larval haemolymph rises and then falls shortly before ecdysis; and these changes in the ecdysone titres mediate the temporal sequence of the developmental processes (Riddiford, 1985; Braquart et. al., 1996). So, by manipulating ecdysone level in the larval instars their growth and development can easily be controlled as reported from the lepidoteran pests of agricultural crops (Blackford and Dinan, 1997a, b; Tanaka and Naya 1995).

A high dose of ecdysone viz., $1400 \mathrm{mg}$ (a.i.)/litre of solution produced significant larval mortality in lady beetle, Coleomegilla maculata (Deg.), important egg predator of european corn borer (Trisyono et. al., 2000). The authors also observed that ecdysone treatment at low doses $(100 / 200$ mg (a.i.)/litre) caused $100 \%$ mortality of the larvae of the host (Ostrinia nubilalis Hubner). Other published reports also showed that synthetic ecdysones were potential control

Table III. Effect of ecdysone treatment for different durations to 1-day old pupae on the developmental time and metamorphosis in the following generation of $T$. castaneum $(\mathrm{N}=30)$.

\begin{tabular}{|c|c|c|c|c|}
\hline \multirow[t]{3}{*}{ Parameter } & \multirow[t]{3}{*}{ Concentrations $(\mu \mathrm{l} / \mathrm{kg})$} & \multicolumn{3}{|c|}{ Exposure period (\%) } \\
\hline & & 1-day & 3-day & 5-day \\
\hline & & Mean \pm SE & Mean \pm SE & Mean \pm SE \\
\hline \multirow{8}{*}{ Larval period (day) } & 0 (Control) & $23.17 \pm 0.44$ & $23.17 \pm 0.44^{\mathrm{a}}$ & $23.17 \pm 0.44^{\mathrm{a}}$ \\
\hline & 10 & $24.00 \pm 1.45$ & $24.67 \pm 0.66$ ab & $25.00 \pm 0.50 \mathrm{ab}$ \\
\hline & 20 & $24.33 \pm 0.17$ & $24.83 \pm 0.44^{\mathrm{ab}}$ & $25.50 \pm 0.76^{\mathrm{ab}}$ \\
\hline & 40 & $24.83 \pm 0.33$ & $24.17 \pm 0.73^{b}$ & $25.67 \pm 0.60^{a b}$ \\
\hline & 80 & $25.50 \pm 1.50$ & $25.33 \pm 0.73 \mathrm{ab}$ & $25.33 \pm 0.60^{a b}$ \\
\hline & 160 & $26.33 \pm 1.64$ & $25.33 \pm 0.88$ ab & $26.50 \pm 0.50^{b}$ \\
\hline & 320 & $25.17 \pm 0.93$ & $26.17 \pm 0.93^{a b}$ & $26.00 \pm 1.90^{\mathrm{ab}}$ \\
\hline & 640 & $25.83 \pm 1.09$ & $27.33 \pm 1.30^{b}$ & $27.00 \pm 1.32^{b}$ \\
\hline \multirow{8}{*}{ Pupal period (day) } & 0 (Control) & $9.50 \pm 0.29^{\mathrm{a}}$ & $9.50 \pm 0.29^{a}$ & $9.50 \pm 0.29^{a}$ \\
\hline & 10 & $10.33 \pm 0.17^{\mathrm{ab}}$ & $11.00 \pm 0.29$ ab & $10.67 \pm 0.33$ ab \\
\hline & 20 & $10.83 \pm 0.17 \mathrm{ab}$ & $11.50 \pm 1.04$ ab & $11.67 \pm 0.60 \mathrm{ab}$ \\
\hline & 40 & $11.17 \pm 0.73 \mathrm{ab}$ & $11.67 \pm 0.94 \mathrm{ab}$ & $11.67 \pm 0.94 \mathrm{ab}$ \\
\hline & 80 & $11.50 \pm 1.53^{a b}$ & $11.87 \pm 0.73 \mathrm{ab}$ & $12.00 \pm 1.04 \mathrm{ab}$ \\
\hline & 160 & $11.83 \pm 1.09 \mathrm{ab}$ & $12.00 \pm 0.58 \mathrm{ab}$ & $12.67 \pm 0.17 \mathrm{abc}$ \\
\hline & 320 & $12.67 \pm 0.17 \mathrm{ab}$ & $13.33 \pm 0.93^{b}$ & $13.17 \pm 0.83 b c$ \\
\hline & 640 & $13.17 \pm 1.09^{b}$ & $14.17 \pm 0.17^{b}$ & $14.33 \pm 0.17^{c}$ \\
\hline \multirow{8}{*}{$\begin{array}{l}\text { Deformity } \\
\text { (\%) }\end{array}$} & 0 (Control) & $0^{\mathrm{a}}$ & $0^{\mathrm{a}}$ & $0^{\mathrm{a}}$ \\
\hline & 10 & $0.89 \pm 0.48^{\mathrm{ab}}$ & $0.66 \pm 0.66 \mathrm{ab}$ & $0.77 \pm 0.45^{\mathrm{ab}}$ \\
\hline & 20 & $1.15 \pm 1.15^{a b}$ & $2.26 \pm 0.17$ ab & $0.95 \pm 0.95 \mathrm{ab}$ \\
\hline & 40 & $2.69 \pm 1.76$ ab & $2.58 \pm 1.09$ ab & $1.30 \pm 0.89 \mathrm{ab}$ \\
\hline & 80 & $3.12 \pm 0.87 \mathrm{abc}$ & $2.92 \pm 1.72^{a b}$ & $2.06 \pm 1.17$ ab \\
\hline & 160 & $4.10 \pm 1.34$ bc & $2.95 \pm 0.76^{a b}$ & $2.41 \pm 1.04 \mathrm{abc}$ \\
\hline & 320 & $5.50 \pm 1.12^{c}$ & $3.42 \pm 2.29^{b}$ & $3.98 \pm 0.75 b c$ \\
\hline & 640 & $5.84 \pm 2.27^{\mathrm{a}}$ & $3.72 \pm 1.37^{\mathrm{b}}$ & $5.97 \pm 2.33^{c}$ \\
\hline
\end{tabular}

N.B. Mean with the same letter are not significantly different. 
agents against the lepidopterans (Dhadialla et. al., 1998, Seymour et. al., 1996, Trisyno and Chippendale, 1997,1998). The authors reported that ecdysone treatment was significantly more toxic to the larvae and eggs of corn borers than the insecticide carbaryl. subsequently transmitted the action to the next generation of $T$. castaneum which received no further treatment. The development of immature stages was slow and finally the $\mathrm{F}_{1}$ adult emergence was decreased compared to the control batch.

Table IV. Pupal and adult recovery (\%) of $\mathrm{F}_{1}$ T. castaneum when the pupae of parental generation were exposed to ecdysone-treated food for different exposure periods $(\mathrm{N}=30)$.

\begin{tabular}{|c|c|c|c|c|c|c|c|}
\hline \multirow[t]{3}{*}{ Parameter } & \multirow{3}{*}{$\begin{array}{l}\text { Concentrations } \\
\qquad(\mu \mathrm{l} / \mathrm{kg})\end{array}$} & \multicolumn{6}{|c|}{ Age of treated pupae } \\
\hline & & \multicolumn{2}{|c|}{ 1-day treated pupae } & \multicolumn{2}{|c|}{ 3-day treated pupae } & \multicolumn{2}{|c|}{ 5-day treated pupae } \\
\hline & & Mean \pm SE & PRC & Mean \pm SE & PRC & Mean \pm SE & PRC \\
\hline \multirow{8}{*}{ Pupal recovery (\%) } & 0 (Control) & $98.70 \pm 0.89^{a}$ & - & $98.70 \pm 0.89$ & - & $98.70 \pm 0.89$ & \\
\hline & 10 & $98.07 \pm 0.63^{a b}$ & 0.64 & $98.03 \pm 0.51$ & 0.68 & $98.21 \pm 0.24$ & 0.50 \\
\hline & 20 & $97.03 \pm 0.27 \mathrm{abc}$ & 1.69 & $98.45 \pm 0.47$ & 0.22 & $97.15 \pm 0.84$ & 1.57 \\
\hline & 40 & $96.26 \pm 1.96 \mathrm{abc}$ & 2.47 & $98.55 \pm 0.43$ & 0.23 & $97.29 \pm 0.44$ & 1.43 \\
\hline & 80 & $95.01 \pm 3.07 \mathrm{bc}$ & 3.74 & $98.47 \pm 0.66$ & 0.15 & $97.51 \pm 1.09$ & 1.20 \\
\hline & 160 & $95.08 \pm 0.93 \mathrm{bc}$ & 3.67 & $97.32 \pm 0.89$ & 1.07 & $97.55 \pm 0.80$ & 1.17 \\
\hline & 320 & $94.26 \pm 1.61 \mathrm{bc}$ & 4.50 & $97.64 \pm 0.27$ & 1.40 & $96.31 \pm 2.53$ & 2.42 \\
\hline & 640 & $94.86 \pm 3.05^{\mathrm{c}}$ & 3.89 & $97.03 \pm 2.43$ & 1.69 & $95.79 \pm 0.80$ & 2.95 \\
\hline \multirow{8}{*}{ Adult recovery (\%) } & 0 (Control) & $99.49 \pm 0.51^{\mathrm{a}}$ & - & $99.49 \pm 0.51^{a}$ & - & $99.49 \pm 0.51^{\mathrm{a}}$ & - \\
\hline & 10 & $98.14 \pm 0.43^{a}$ & 1.36 & $95.43 \pm 1.60^{a b}$ & 4.80 & $97.94 \pm 1.18$ ab & 1.56 \\
\hline & 20 & $97.88 \pm 0.09^{\mathrm{a}}$ & 1.62 & $94.91 \pm 3.79^{b}$ & 4.60 & $94.94 \pm 1.02 \mathrm{a}$ abc & 4.57 \\
\hline & 40 & $97.54 \pm 1.64^{\mathrm{a}}$ & 1.96 & $94.69 \pm 1.84 \mathrm{~b}^{\mathrm{b}}$ & 4.82 & $94.20 \pm 0.62 \mathrm{bc}$ & 5.32 \\
\hline & 80 & $96.63 \pm 1.08^{\mathrm{a}}$ & 2.87 & $93.51 \pm 1.11 b^{b}$ & 6.01 & $93.49 \pm 2.40 \mathrm{bc}$ & 6.03 \\
\hline & 160 & $93.38 \pm 3.66^{\mathrm{ab}}$ & 6.14 & $94.07 \pm 1.85$ bc & 5.45 & $91.47 \pm 0.97^{\mathrm{c}}$ & 8.06 \\
\hline & 320 & $89.01 \pm 3.15^{b}$ & 10.53 & $93.18 \pm 0.12^{b}$ & 6.34 & $89.86 \pm 2.15^{c}$ & 9.68 \\
\hline & 640 & $87.72 \pm 2.06^{b}$ & 11.83 & $89.99 \pm 3.21^{\mathrm{c}}$ & 9.55 & $89.86 \pm 1.55^{\mathrm{c}}$ & 9.68 \\
\hline
\end{tabular}

N.B. Mean with the same letter are not significantly different.

Silhacek et. al. (1990) reported that synthetic ecdysteroids inhibited larval growth in Plodia interpunctella (Hubner), a stored product moth pest at $5 \mathrm{ppm}$; and a higher dose produced $90-100 \%$ mortality. Among the coleopteran pests of the stored products F1 population of $T$. castanuem and Rhyzopertha dominica F. were almost completely controlled by RH-5859 (Kostyukovsky et. al., 2000). However, the authors found that the compound was inactive against the internal grain feeder, Sitophilus oryzae L.

Research works conducted on the latent effects of ecdysone treatment to the pupae of stored product moths or beetles are scanty. Results of the present experiments showed that the contact action of ecdysone to the pupae may interfered the actual growth and development in subsequent two generations of $T$. castaneum. Though the pupae received direct contact treatment, and completed metamophioses within the same range like the untreated control pupae but adult emergence was reduced in the treated pupae. The percentage of emergene was mainly affected due to the abnormal adult progeny. Ecdysone treatments to the pupae for longer or shorter periods pronounced similar effects.

Results of the second experiment revealed that neither the pupae nor the adults could metabolize the compound and
Potential effect of ecdysone depends on the developmental age of the treated insect and the degrees of development in a population are never identical (Steel and Vafopoulou, 1989). Hence, effects of ecdysone varied greatly with the concentrations and exposure durations though the treated pupal age was the same in the experimental population.

\section{Conclusion}

The present results state that ecdysone treatment to immature stages of $T$. castaneum could hamper their normal metamorphoses. Higher ecdysone titre in pupae would normally enhance adult emergence but in this experiment due to abnormal metamorphosis the percentage of viable adults were reduced not only in the parental generation but in the following generation also. More research work is needed by allowing different ages of immature stages of different coleopteran pests of the stored products to ecdysone. The effectiveness of ecdysone as a ecofreindly agent that might be used in the management of the coleopteran insect pests in the storage ecosystem.

\section{Acknowledgement}

The authors are thankful to Dr. Manabu Kamimura, Senior 
Researcher, Insect Growth Regulation Laboratory, NIAS, Tsukuba, Japan for supplying the ecdysone as a gift to Dr. A.M. Saleh Reza.

\section{References}

Blackford M. and Dinan L. (1997a) The tomato moth Lacanobia obracea (Lepidoptera: Noctuidae) detoxifies ingested 20-hydroxyecdysone, but is susceptible to the ecdysteroid agonists RH-5849 and RH-5992. Insect Biochem. Molecular Biol. 27: 166-177.

Blackford M. and Dinan L. (1997b) The effects of regested 20-hydroxyecdysone on the larvae of Aglais urticae, Inachis io, Cynthia cardui (Lepidoptera: Nymphalidae) and Tyria jacobae (Lepidoptera: Arctudae). J. Insect Physiol. 44: 166-172.

Braquart C., Bouhin H., Quennedey A. and Delachambre J. (1996) Up-regulation of an adult cuticular gene by 20hydroxyecdysone in insect metamorphosing epidermis cultured in vitro. European J. Biochem. 240: 336-341.

Dhadialla T. S., Carlson G. R. and Le D. P. (1998) New insecticides with ecdysteroidal and juvenile hormone activity. Ann. Rev. Entomol. 43: 545-569.

Fox P. (1990) Insect Growth Regulators. PJB Publ. Ltd. Richmond, UK, 102pp.

Halstead T. J. H. (1963) External sex differentiation in stored products Coleoptera. Bull. Ent. Res., 54:119-134.

Hami M., Taibi F., Smagghe G. and Soltani-Mazouni N. (2006) Comparative toxicity of three ecdysone agonist insecticides against the Mediterranean flour moth. Communication in Agricultural and Applied Biological Sciences, Ghent University 70/4: 767-773.

Kostyukovsky M., Chen B., Atsmi S. and Shaaya, E. (2000) Biological activity of two juveniles and two ecdysteriods against three stored product insects. Insect Biochem. Molecular Biol. 30(8-9): 891-897.

Lanot R., Dorn A., Gunster B., Thiebold J., Lagueux M. and Hoffmann, J. A. (1989) Functions of ecdysteroids in oocyte maturation and embryonic development of insects. In: Ecdysone from chemistry to mode of action. George Thieme, Verlog, Germany.

Reza A. M. S., Kanamori Y., Shinoda T., Shimura S., Mita K., Nakahara Y., Kiuchi M. and Kamimura M. (2004) Hormonal control of a metamorphosis-specific transcriptional factor Broad-Complex in Silkworm. Comp. Biochem. Physiol. Part B 139: 753-761.

Riddiford L. M. (1985) Hormone action at the cellular level.
In: Comprehensive insect physiology, biochemistry and pharmacology (G.A. Kercut \& L.I. Gilbert eds.), 8, Pergaman Press, Oxford, pp. 37-84.

Seymour R. C., Campbell J. B. and Wright, R. J. (1996) Control of European corn borer larva on reproductive stage field corn. Arthropod Management Tests 21: 228.

Silhacek D. L., Oberlander H. and Porcheron, P. (1990) Action of RH-5849, a non-steroidal ecdysteroid mimic on Plodia interpunctella (Hubner) in vitro and in vivo. Arch. Insect Biochem. \& Physiol., 15: 201-212,

Steel C. G. H. and Vafopoulou X. (1989) Ecdysteroid titer profile during growth and development of arthropods. In: Ecdysone; from chemistry to mode of action ( $\mathrm{J}$. Koolman ed.). Thieme Medical Publishers, Inc., New York. pp. 221-231.

Strong R.G. and Diekman J. (1973) Comparative effectiveness of fifteen insect growth regulators against several pests of stored products. J. Econ. Entomol. 66: 1167-1173.

Tanaka Y. and Naya S. ( 1995) Dietary effect of ecdysone and 20-hydroxyecdysone on larval development in two lepidopteran species. Appl. Ent. Zool. 30: 285-294.

Trisyono A. and Chippendale G.M. (1997) Effect of the monsteroidal ecdysone against methoxyfenozide and tebufenozide on the European cron borer (Lepidoptera: Pyrallidae). J. Econ. Entomol, 90: 1486-1492.

Trisyono A. and Chippendal G. M. (1998) Effect of the ecdysone agonists, RH-2485 and tebufenozide, on the southwestern corn borer, Diatraea grandiosella. Pest. Sci. 53: 177-185.

Trisyono A., Puthter B. and Chippendale, G.M. (2000) Effects of the ecdysone agonists, methafenozide and tebufexozide, on the lady beetles, Coleomegilla maculata. Ent. exp. et. appl. 24: 103-105.

Tukey J. W. (1953) Multiple comparisons., In: Biostatistical Analysis, (J H. Zar ed.), 4th edition, chapter 11. Prentice Hall International, Inc.

Williams C. M. (1956) The juvenile hormone of insects. Nature (London), 178: 212-213.

Wing H. D. and Aller H. E. (1990) Ecdysteroid againsts as novel insect growth regulators. In: Pesticides and Alternatives (J.E. Casida ed.). Elsevier Science Publishers, Amsterdam, Oxford, New York, pp. 251-257.

Received : April 01, 2009;

Accepted : July 09, 2009 